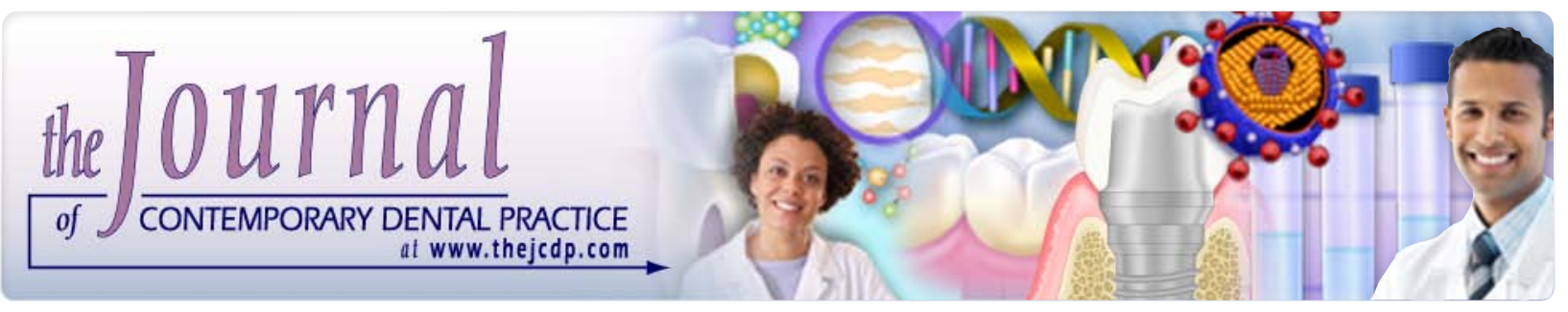

\title{
A New Concept in Restorative Dentistry: Light-Induced Fluorescence Evaluator for Diagnosis and Treatment: Part 1 - Diagnosis and Treatment of Initial Occlusal Caries
}

Elodie Terrer, DDS; Stephen Koubi, DDS; Alexandro Dionne; Gauthier Weisrock, DDS; Caroline Sarraquigne; Alain Mazuir; Hervé Tassery, DDS, MS, PhD

\begin{abstract}
Aim: The objective of this in vivo experiment is to propose an innovative therapeutic concept using a light-induced fluorescence evaluator for diagnosis and treatment (LIFEDT) that is based on the imaging and autofluorescence of dental tissues.

Background: Processes with the aim of diagnosing carious lesions in the initial stage with optimum sensitivity and specificity employ a wide variety of technologies, but like the conventional diagnosis tools, they remain either inefficient or too subjective.

Technique: This experiment evaluated a fluorescence light-induced camera that illuminates tooth surfaces within an excitation radiation band of light with a wavelength of $450 \mathrm{~nm}$ and facilitates a high magnification image.
\end{abstract}

Conclusions: An analysis of 50 occlusal grooves revealed three clinical forms of enamel caries:

(1) enamel caries on the surface, (2) suspicious grooves with a positive autofluorescent red signal, and (3) suspicious grooves with a neutral fluorescent dark signal. Two decision-making diagrams were proposed in accordance with international recommendations for preventive dentistry, but modified as a result of the accurate information obtained with this new LIFEDT device.

Clinical Significance: The lighting of suspect occlusal grooves with the SoproLife ${ }^{\circledast}$ camera

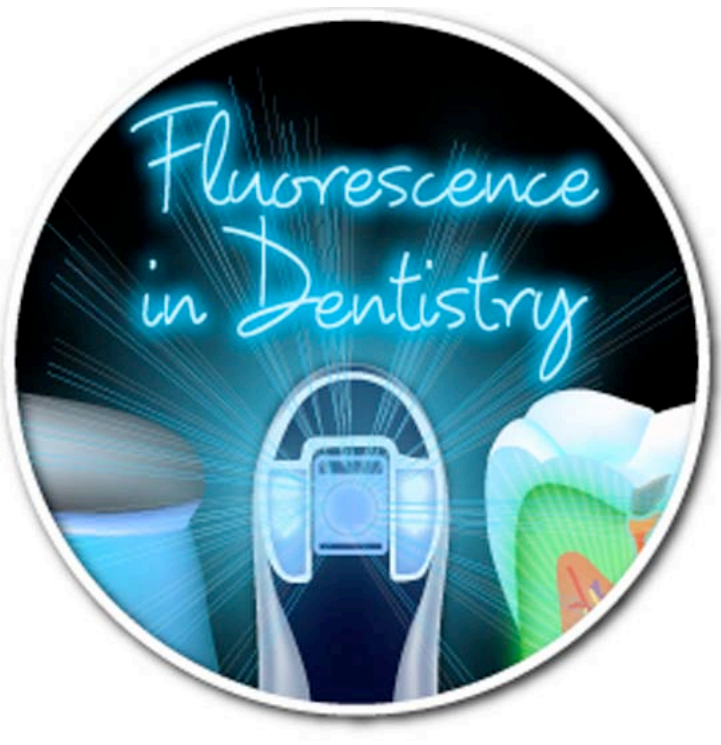

enables observation of any variations in the optical properties to refine a caries diagnosis and facilitates more than a 50x magnification of occlusal groove anatomy to provide additional information on the carious potential of the tooth surface.

Keywords: Diagnosis, autofluorescence, LIFEDT concept, minimally invasive dentistry.

Citation: Terrer E, Koubi S, Dionne A, Weisrock G, Sarraquigne C, Mazuir A, Tassery H. A New Concept in Restorative Dentistry: Light-Induced 
Fluorescence Evaluator for Diagnosis and Treatment: Part 1 - Diagnosis and Treatment of Initial Occlusal Caries. J Contemp Dent Pract [Internet]. 2009 Nov; 10(6):086-094. Available from: http://www.thejcdp.com/journal/view/ volume10-issue6-terrer.

\section{Background}

Processes with the aim of diagnosing carious lesions in the initial stage with optimum sensitivity and specificity employ a variety of technologies such as laser, ${ }^{1,2}$ fluorescence and autofluorescence, ${ }^{3.4 .5}$ electric current, tomographic imaging, and image processing. ${ }^{6}$ Despite the availability of these technologies, their high cost, size, excessive variable sensitivity, and specificity ${ }^{\underline{7}}$ have prohibited their use on a daily basis like conventional diagnosis tools such as film or digital radiography. These different means of analysis are also dependent on the experience of clinicians and their practice of viewing magnified images using a magnifying glass or microscope.$^{8}$ Conventional diagnosis strategies for caries detection like visual observation or probing with a dental instrument are unfortunately based on subjective criteria such as lesion color and texture. There is a profound need for a fluorescence device that combines magnification and amplification of the visual signal to assist clinicians with the assessment of tooth structure. Defining new diagnostic and treatment strategies and related instrumentation is consistent with the

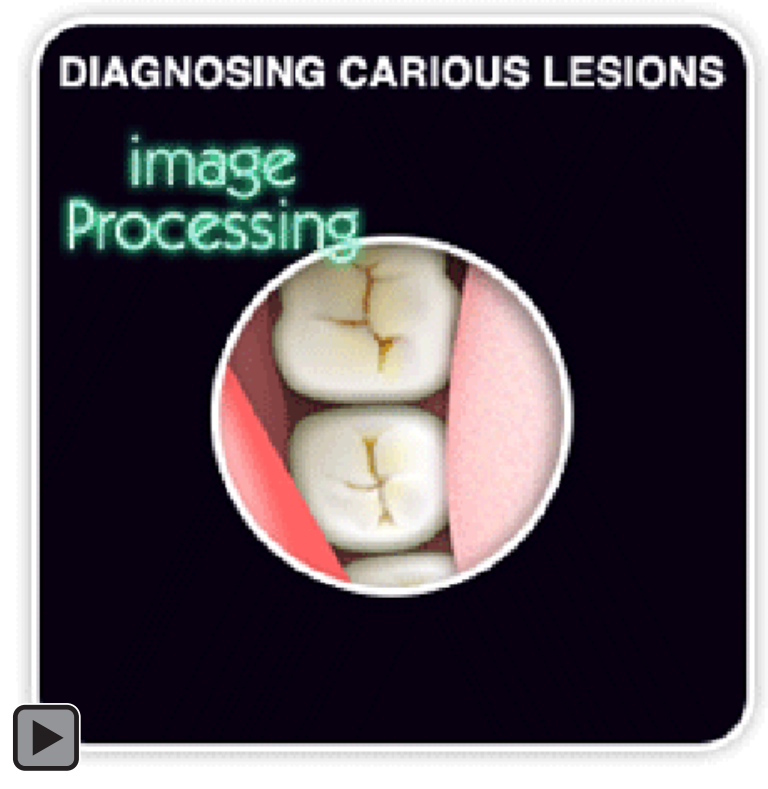

principles of contemporary restorative dentistry. These principles call for a comprehensive patient approach in terms of caries risk assessment, diagnosis, and appropriate therapies that are consistent with the concepts of minimally invasive dentistry (MID), or minimal Intervention (MI), terms accepted by the Federation Dentaire Internationale in $2000 .^{9}$

Proper caries management dictates that a clinician conduct an analysis of the cariological context of the patient, or their caries risk level, over time. Mount et al..$^{10}$ defined caries progression on the basis of lesion site and stage on a scale from 0 to 4 . Pitts ${ }^{6.11}$ described the progression of all the stages of dental caries in addition to six levels of severity with the International System for Caries Detection and Assessment (ICDAS) using an iceberg metaphor. Caries risk can be defined in the form of a Cariogram with three levels of caries risk ${ }^{12}$ or in accordance with the Caries Management by Risk Assessment (CAMBRA) system ${ }^{13}$ associated with the ICDAS II, which defines four levels of caries risk and describes ad hoc therapies..$^{13,14}$

The objective of this in vivo experiment is to propose an innovative therapeutic concept compliant with international recommendations using a light-induced fluorescence evaluator for diagnosis and treatment (LIFEDT) that is based on the imaging and autofluorescence of dental tissues.

\section{Technique}

\section{The SoproLife ${ }^{\circledR}$ Camera}

Banerjee et al. ${ }^{3-5}$ described an optical property of dental tissues when they are illuminated at a certain wavelength, or autofluorescence. Based on this principle, an experimental LED camera (SoproLife ${ }^{\circledR}$ ) was developed and clinically validated in the Department of Restorative Dentistry of the University of the Mediterranean in Marseille, France. The patented technology was developed by Sopro-Acteon Imaging in $\mathrm{La}$ Ciotat, France. The technique utilizes an LED camera that can illuminate tooth surfaces within a radiation band (wavelength $450 \mathrm{~nm}$ with a bandwidth of $20 \mathrm{~nm}$, centered at $\pm 10 \mathrm{~nm}$ around the excitation wavelength) that is situated in the visible domain. This provides an anatomical image superimposed on an autofluorescence 


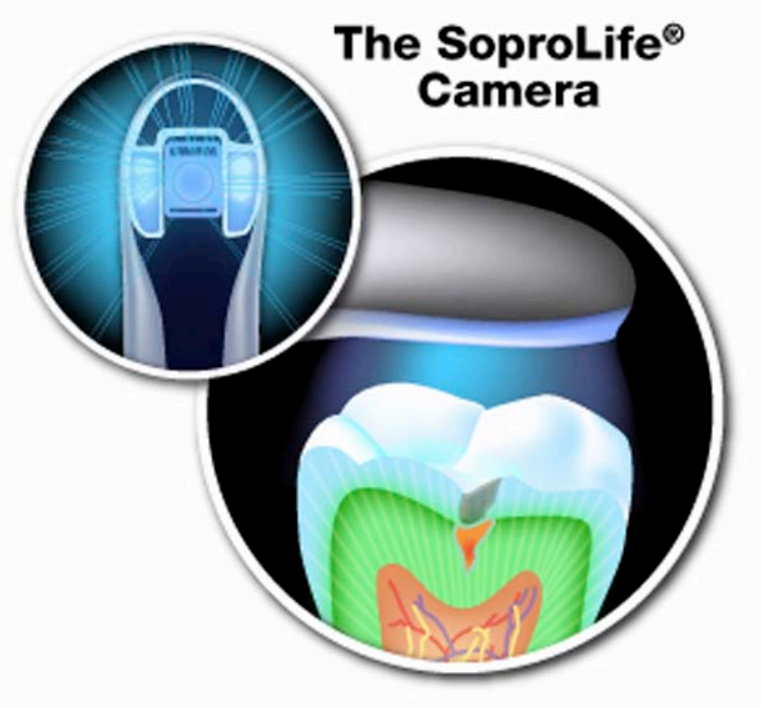

image emitted by the illuminated teeth. This camera can detect and locate differences in density, structure, and/or chemical composition of a biological tissue subjected to continuous lighting in one frequency band while making it generate a fluorescence phenomenon in a second frequency band. The camera is equipped with an image sensor (a 0.25-inch CCD sensor) consisting of a mosaic of pixels covered with filters of complementary colors. The data collected, relating to the energy received by each pixel, enable an image of the tooth to be retrieved. The fluorescence signals corresponding to the more or less damaged parts of a tooth are amplified selectively to accentuate the specificity of the fluorescence images. The wavelength of the autofluorescence signal varies according to the density and chemical composition of the tissue on its surface and subsurface. The different layers of tissue and their characteristics influence its response, the same as for material deposits. As a result, any carious lesion or diseased tissue will be detected by variation in the autofluorescence of its tissues in relation to a healthy area of the same tooth. The camera also provides a magnification range of more than 50x of the tooth surface on a visual screen using three illumination modes: daylight, diagnosis mode, and treatment mode. The images are observed in real time on a big LED screen and can be recorded in a computer using special imaging software (Sopro imaging software Life mode).

The LIFEDT Concept

Except for DIAGNOdent (KavoDental, GmbH, Biberach/Riss, Germany), there are only a few diagnosis tools available for assessment of site 1 stage 0 , and 1 or 0 to 3 ICDAS II code lesions that are genuinely usable on a regular basis. ${ }^{1.2}$ These tools provide clinical assistance in the form of an alarm signal in the presence of dentinal caries but have shortcomings in terms of low specificity and false- positive signals. As an alternative, the LIFEDT concept proposes the use of decision-making diagrams in conjunction with the clinical information gathered from the intraoral autofluorescent/LED camera and taking into account international recommendations for caries diagnosis. These diagrams will be discussed later.

The examination of occlusal fissures using a dental mirror and probing should be abolished because it cannot reveal the true complexity, anatomical configuration, and degree of groove fissuration in order to assess the difficulty the patient encounters when attempting to clean them as a part of his or her home care regimen. ${ }^{15-17}$ However, a magnification of more than 50x of the occlusal groove anatomy and modifications to the autofluorescence signal via the LED camera produce images of the enamel-dentinal structures surrounding the groove that provide invaluable information about potential risk of caries infiltration and about the penetration level of the acid front of an advancing lesion. On the other hand, no information is provided via the camera regarding the complex bacterial ecology ${ }^{18}$ in terms of lesion composition or interactions.

The LED camera is not a replacement for the clinician's diagnostic capability; it is a device designed to expand the availability of information for the clinician. The camera provides the clinician with a magnified view of occlusal groove anatomy and its complexity, and generates a modified autofluorescent image of carious tissue or hard tissue malformations in relation to an adjacent healthy area of the same tooth.

\section{Methods and Materials}

The key principle employed in the use of the SoproLife ${ }^{\circledast}$ camera is to observe consistent variation in the enamel-dentinal tissue autofluorescence in relation to a healthy area of a tooth.

\section{Observation Methods}

Without any probing before or after observation, a total of 50 randomly selected dental grooves 
Table 1. Distribution of cases of the three forms of enamel caries in this review.

\begin{tabular}{|c|c|c|}
\hline $\begin{array}{c}\text { Clinical } \\
\text { Form }\end{array}$ & Description & $\begin{array}{c}\text { Number } \\
\text { of Cases }\end{array}$ \\
\hline $\mathbf{1}$ & Enamel caries (presumably on the surface). (Figures 2 and 3) & 12 \\
\hline $\mathbf{2}$ & $\begin{array}{c}\text { Suspicious grooves with a positive autofluorescent signal. The } \\
\text { bottom of the groove appears bright red in diagnosis mode. } \\
\text { (Figure 6) }\end{array}$ & 18 \\
\hline $\mathbf{3}$ & $\begin{array}{c}\text { Suspicious grooves with a neutral fluorescent signal, or } \\
\text { autofluorescence masking effect. The bottom of the groove } \\
\text { appears black in diagnosis mode. (Figure 11) }\end{array}$ & 20 \\
\hline
\end{tabular}

located on the occlusal surfaces of mandibular or maxillary molars were illuminated using the SoproLife ${ }^{\circledast}$ camera and analyzed. The teeth were chosen from 14 female and 11 male dental students using visual inspection with 3.5x magnifying glasses (I.Dentix, Strasbourg, France), a SoproLife ${ }^{\circledast}$ camera in daylight mode, and bitewing radiographs. The mean was two suspicious occlusal grooves per student. The dental students all had favorable socioeconomic backgrounds. The DIAGNOdent was used to establish an average value of its signal as a reference point since any value greater than 20 presupposes the existence of at least enameldentinal caries. The inclusion criteria consisted of all suspicious grooves in terms of color and depth. The exclusion criteria consisted of carious lesions already extending to the dentin and lesions with cavitations.

\section{Results}

After analysis of 50 grooves of presumed stages: 0-110 or 0-3 ICDAS11, three clinical forms of enamel caries were observed (Table 1).

\section{Form 1: Enamel Caries.}

An example of enamel caries (Form 1) is shown of tooth \#18 with caries presumably on the occlusal surface (Figure 1).

Analysis of the acquired data included the following:

- Radiographic Film Data: None or uninterpretable.

- DIAGNOdent Data: Average value 14-16.
- SoproLife ${ }^{\circledR}$ Camera Data: The magnified surface in daylight mode of the occlusal face reveals the extent of the caries (Figure 2), and the diagnostic mode (Figure 3 ) confirms the presence of a demineralized enamel layer by absorbing the blue signal homothetic to the demineralized surface visible in daylight.

Form 2: Suspicious Grooves with a Positive Autofluorescent Signal.

A radiographic example of a suspicious groove in tooth \#17 is shown in Figure 4.

With a positive autofluorescent signal, the bottom of the groove appears bright red in diagnosis mode (Figures 5 and 6).

Analysis of the acquired data included the following:

- Radiographic Film Data on Tooth \#17: None or uninterpretable.

- DIAGNOdent Data: Average value 20.

- SoproLife ${ }^{\circledast}$ Camera Data: A red autofluorescent signal appeared in the bottom of the suspicious groove. This localized alarm signal requires a prophylactic cleaning of the groove using a sodium bicarbonate abrasion air process to either confirm or invalidate the area of alarm (Figures 7 and 8).

After cleaning, the groove's anatomy is revealed with the red autofluorescence partially disappearing (Figure 7). Examination of the tissues surrounding the groove does not show any major variation in autofluorescence in relation to the adjacent healthy area with a regular acid green appearance (Figure 8, area A). 


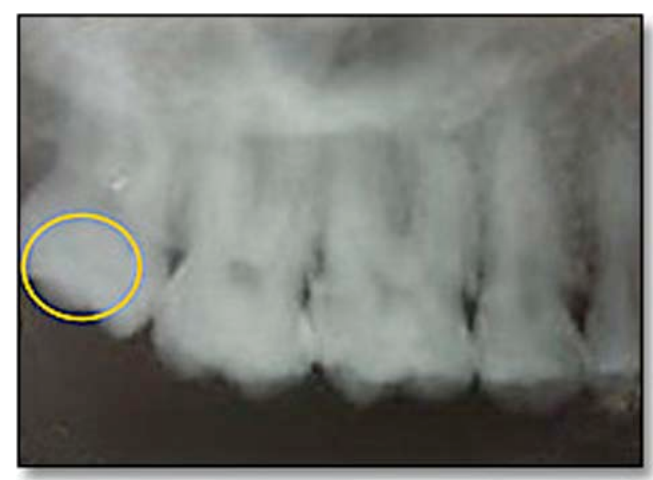

Figure 1. Radiography of tooth 18 . The yellow circle is the suspicious area.

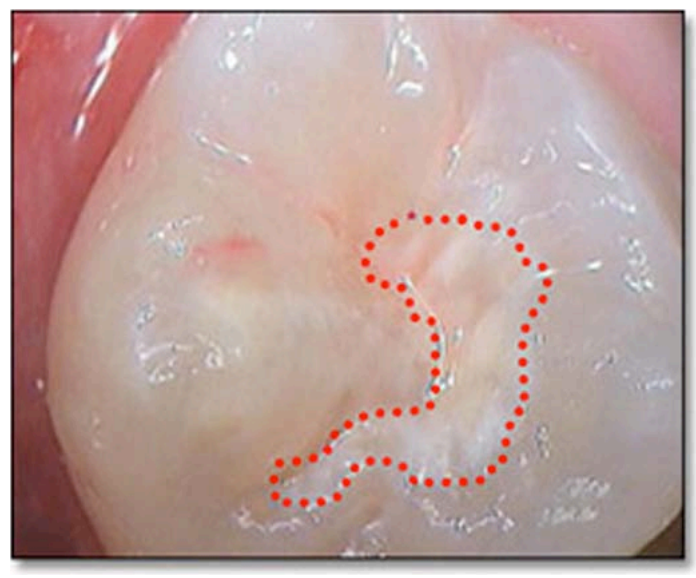

Figure 2. Occlusal surface of tooth \#18 in daylight mode.

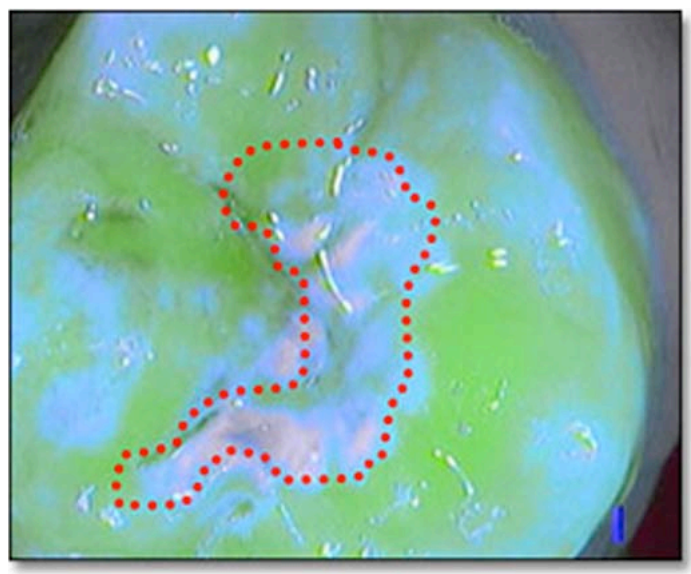

Figure 3. Occlusal surface of tooth \#18 in diagnosis mode. (The red dots outline the porous tissue structure.)

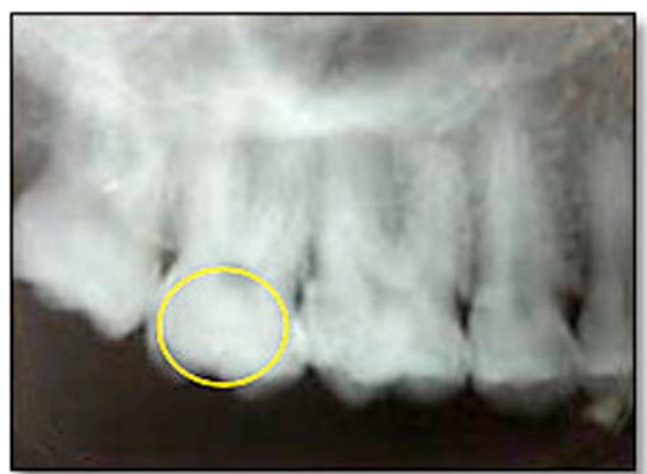

Figure 4. Periapical radiograph of tooth \#17. (The yellow circle identifies the suspicious area.)

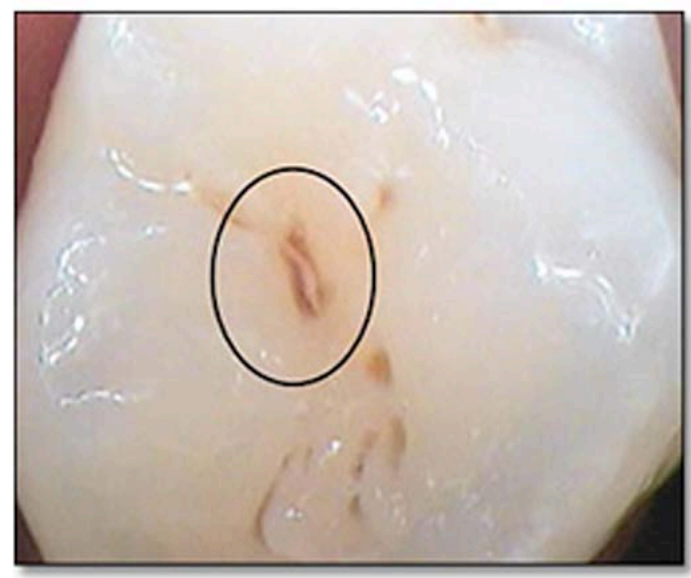

Figure 5. Occlusal surface of tooth \#17 in daylight mode. (A suspicious central groove is shown in the black circle.)

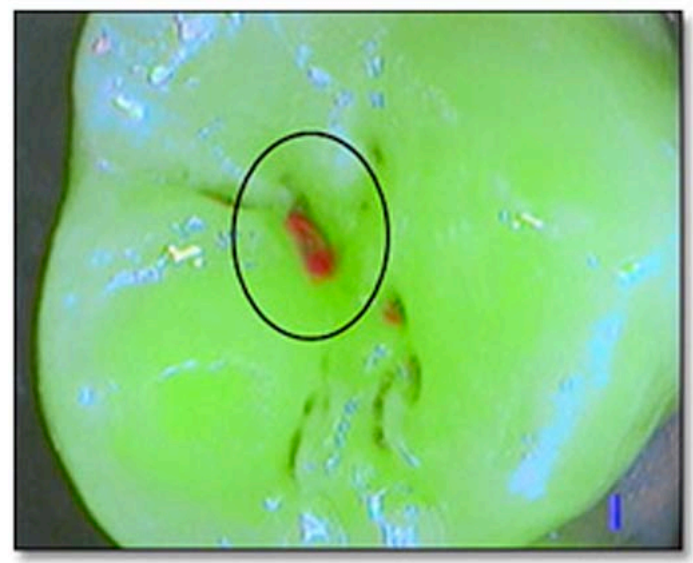

Figure 6. Occlusal surface of tooth \#17 in diagnosis mode. A bright red fluorescent signal appears in the central groove. 


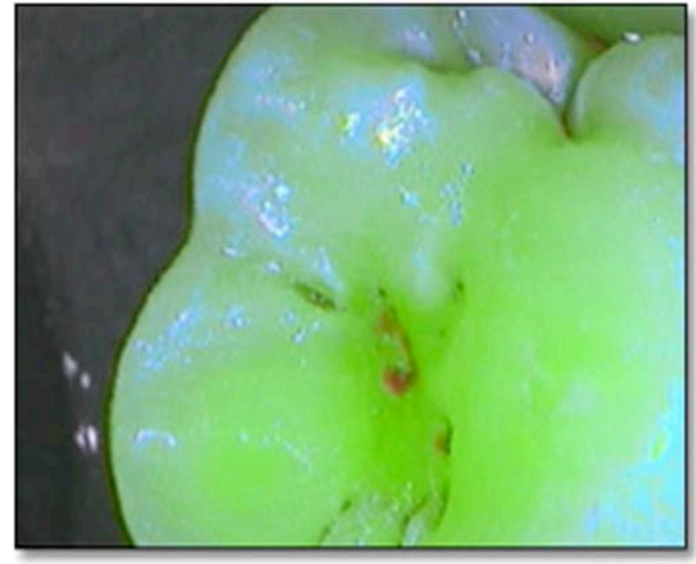

Figure 7. Appearance of the suspicious groove after cleaning with sodium bicarbonate.

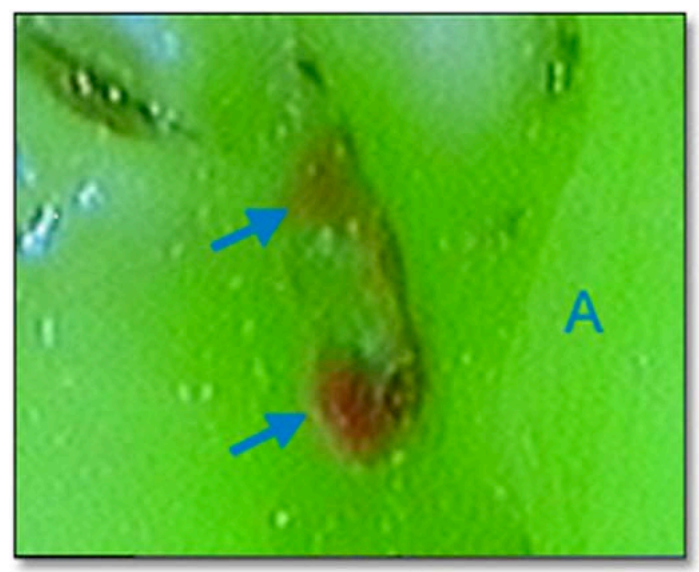

Figure 8. Enlargement of the image (Sopro imaging software). A. Healthy area of the tooth. B. Arrows identify a low-suspicion area due to its shallowness.

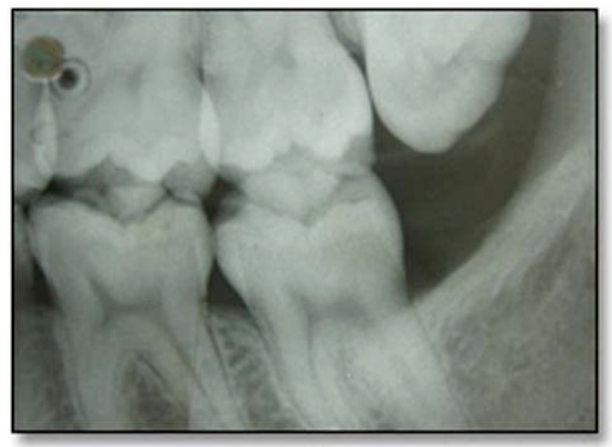

Figure 9. Bitewing radiograph of tooth \#27. (The suspicious area is shown in the dark circle.)
Form 3: Suspicious Grooves with a Neutral Fluorescent Signal.

A radiographic example of a suspicious groove in tooth \#27 is shown in Figure 9.

With a neutral fluorescent signal, or the presence of autofluorescent masking effect, the bottom of the groove appears black in the diagnostic mode, raising the suspicion of a fissured groove (Figures 10 and 11), meaning that you absolutely need to clean the groove and reuse the camera for reevaluation.

Analysis of the acquired data included the following:

- Radiographic Film Data on Tooth \#27: None or uninterpretable.

- DIAGNOdent Data: Average value 20.

- SoproLife ${ }^{\circledR}$ Camera Data: (Figure 11)

- Absence of a red autofluorescence signal or the presence of a fluorescence masking effect (dark black appearance) with the modified acid green fluorescence taking on a darker appearance.

- Precise data on groove fissuration.

Localized variation in autofluorescence (Figure11) from acid green to dark brown is also an alert signal. Air abrasion cleaning with sodium bicarbonate provides useful information on the state of the tissues in the diagnostic mode (Figures 12 and 13).

The option of in situ magnification of the image and the autofluorescent signal shows variations in fluorescence in the main groove (Figure 13) that is more pronounced than the reference fluorescence associated with the healthy tissues in area A. There is a hint of the presence of an isthmus between arrows 2 and 3 .

\section{Decision-Making Diagram for the LIFEDT Concept}

To deal with three kinds of clinical situations, two decision-making diagrams are proposed that are in accordance with the international recommendations for preventive dentistry, ${ }^{13,14}$ and modified because of the additional accurate information provided by the SoproLife ${ }^{\circledR}$ Camera: autofluorescence variations and the magnification. 


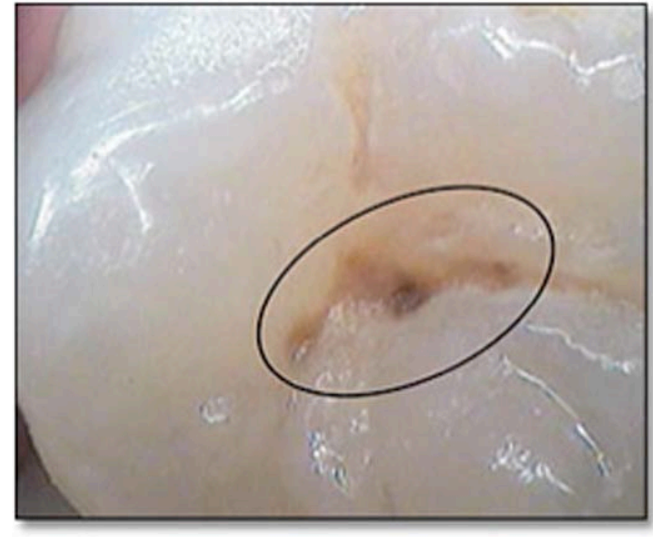

Figure 10. Fissured, suspicious groove in daylight mode.

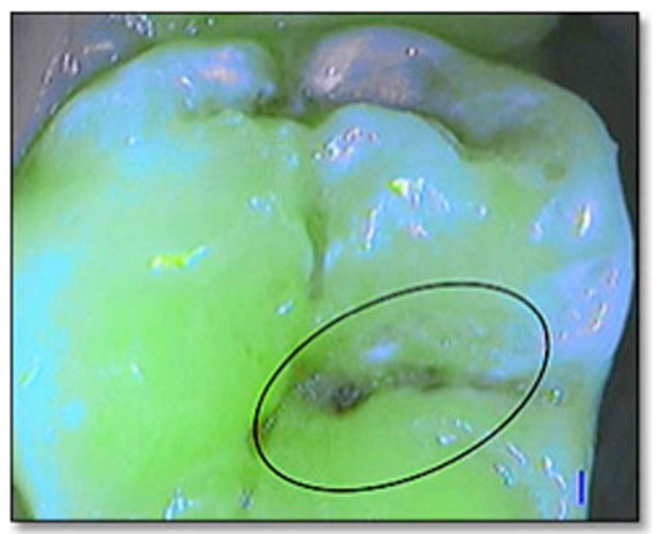

Figure 11. Fissured groove with modified autofluorescence signal (darker appearance) in diagnostic mode.

The first diagram is proposed for use with suspected surface enamel lesions (Form 1) and the second diagram is for use with the other two forms of suspicious grooves observed (Forms 2 and 3).

\section{Discussion}

The information obtained by the SoproLife ${ }^{\circledR}$ camera is interpreted logically according to the caries risk, and the LIFEDT concept suggests therapies in accordance with international recommendations for preventive dentistry, but with greater precision in terms of the system performance, and, of course, its limits. Individuals with visible enamel-dentinal caries, initial enamel lesions (white spots), restorations less than three years old, or with proximal enamel damage (without involvement of the dentin, but

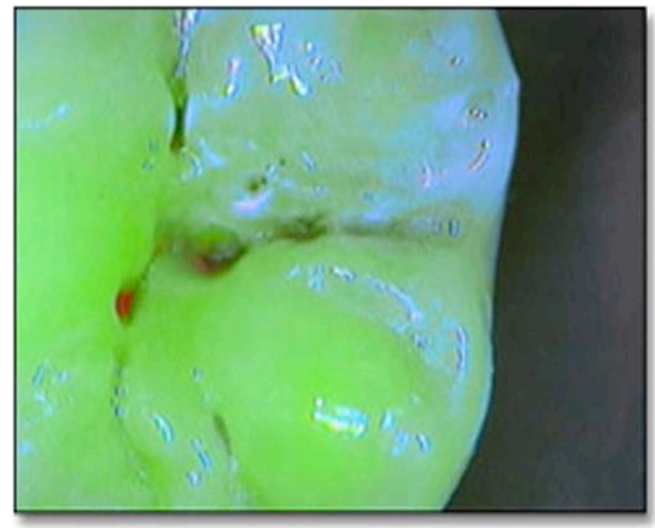

Figure 12. Groove after cleaning in the diagnostic mode.

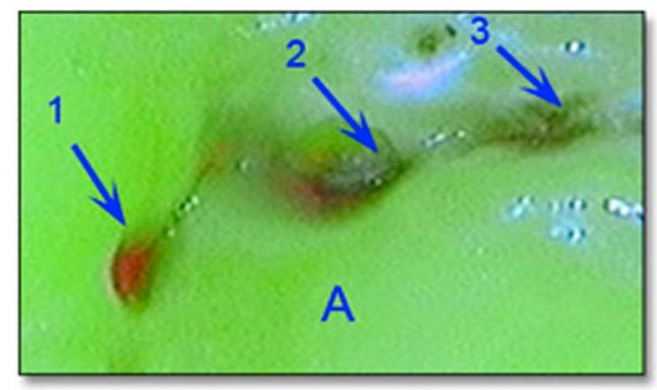

Figure 13. Enlargement of groove with three suspicious areas (arrows 1, 2, 3). Area A indicates a healthy tissue area (diagnostic mode.)

radiographically visible) are considered to be at-risk patients. ${ }^{12,13}$ If oligoptyalism is added to this list, these patients also would be considered a high caries risk. ${ }^{13}$ This would result in four levels of caries risk: low, moderate, high, and extreme. Depending on the social context in many countries, that leaves little room for maneuvereing to find a patient with low caries risk. It is difficult to clinically discriminate between these four levels despite the accuracy of different strategies for caries assessment available. ${ }^{12,13}$ For this reason, only two main caries risk levels (low and high risk) and one exceptional risk level (extremely high level, to accommodate oligoptyalism) were included in the two decision-making diagrams. A moderate risk would actually be considered as a high risk in this system.

The recommendation of the CAMBRA concept ${ }^{13}$ is to apply a sealant for up to level 3 of the ICADS II system, but the CAMBRA diagnosis level is limited by the diagnosis tools themselves. ${ }^{20}$ The potential benefits of the imaging approach 


\section{LIFEDT Decision-Making Diagram \#1}

\section{Form 1: Surface enamel lesions.}

\section{High Caries Risk \\ (Cariogram $^{12}$ or CAMBRA analysis ${ }^{14}$ )}

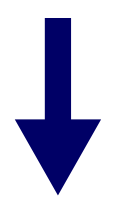

\section{LIFEDT Concept}

- Professional prophylactic cleaning.

- Care with abrasion air in conjunction with sodium bicarbonate as the crystalline structure is highly unstable.

- Brushing 2-3 times per day: $1.1 \%$ NAF toothpaste.

- Xylitol (6 g/day): chewable tablets.

- Application of fluoride varnish (5\% NAF); recall every 3-4 months.

- Application of calcium phosphate-based paste (MI plus GC Tooth mousse, GC Tokyo, Japan).

- Mouthwash: $0.05 \%$ NAF or $0.12 \%$ chlorhexidine: 1 minute every evening.

- Dietary counseling.

- LIFEDT Concept: If the LED camera confirms groove fissuration and any variations in fluorescence, a sealant will be applied using a dental dam.
- Professional prophylactic cleaning.

- Care with abrasion air in conjunction with sodium bicarbonate as the crystalline structure is highly unstable.

- Brushing 2-3 times per day with fluoride toothpaste.

- Application of fluoride varnish (5\% NAF); patient recall every 6 months.

- Application of calcium phosphate-based paste (optional).

- : If the LED camera confirms groove fissuration and any associated variations in fluorescence, a sealant is recommended. 


\section{LIFEDT Decision-Making Diagram \#2}

Forms 2 and 3: Suspicious grooves with fluorescence

altered (red or neutral signal) in relation to a healthy area.

\section{Decision-making criteria for fitting of a sealant:}

\section{LIFEDT Concept}

A. See Diagram \#1 for either high or low caries risk.

B. FluoLED camera data:

- Groove fissuration: Positive criterion whatever the caries risk, due to effectiveness of brushing being impossible to monitor.

- Modification of enamel and dentinal fluorescence of tissues surrounding the groove: Positive criterion whatever the caries risk, as bacterial or acid infiltration is potentially effective. used at present are dependent on assisted clinical decision making. The LIFEDT/SoproLife ${ }^{\circledR}$ camera concept, within the limits of the process, can obtain genuine information on groove complexity. Short of using a costly microscope (20x), this information is not accessible by any means currently available. Common magnified vision using magnifying glasses (3.5x) is simply too weak. In reality clinicians are too often working blindly with regard to caries detection. Magnification of more than 50x provides images of the deep structure of the groove that can be viewed live on a big screen monitor. Such images represent an invaluable aid when choosing the best-suited therapies ${ }^{14}$ such as the application of a varnish, a transparent protective sealant, or just monitoring the status of a potential carious lesion regardless of the patient's caries risk.

The second source of diagnostic information is provided by the modifications in fluorescence (Figures 6 and 11) observed by the clinician to assess the degree of infiltration of dental caries into an occlusal groove. A recent study ${ }^{21}$ compared the performance of fluorescence- based methods (FC VistaProof, Dürr Dental, Bietingen-Bissingen, Germany, DIAGNOdent) with a traditional radiograph examination and an ICDAS II visual examination. ${ }^{22}$ The investigators concluded bitewing radiographs combined with a visual examination ICADII appears to be the best combination for an accurate diagnosis. Unlike the DIAGNOdent, the SoproLife ${ }^{\circledR}$ camera provides an overall image of the clinical situation rather than a point-by-point measurement requiring the judgment of the clinician in all cases. The training and clinical experience of the individual dentist remains a critical element in arriving at an accurate diagnosis and treatment strategy. Therefore, the primary usefulness of the SoproLife ${ }^{\circledR}$ camera in daily practice might be to improve the diagnostic skill of the dentist, subject, of course, to the inherent limits of the present study. In fact it reveals ultra-structural modifications of enamel and dentin due to the carious process and the resulting optical modifications. ${ }^{6}$ Organic deposits, porosities, crystalline destructuring, and the acid front are all capable of disrupting the autofluorescence signal, discoloring, and modifying the brightness 
of the hard tooth structures. ${ }^{3-5,23,24}$ Porous enamel absorbs the incident signal in the blues range of the light spectrum (Figure 3) and the presence of a more complex, deep lesion returns a red (Form 2) or dark brown (Form 3) signal. At present there is no rational explanation of why these two signal types (red or dark brown) are generated, but the presence of organic matter in the bottom of the groove appears to be correlated with the red signal.

Furthermore the system does not address the issue of bacterial ecology. This can be determined using reliable bacterial tests such as GC Saliva Check SM, GC Plaque-check+pH (GC, Tokyo, Japan), and Cariscreen (Oral Biotech, Albany, OR, USA). ${ }^{18}$ In the presence of a highrisk oral ecology, any fissured groove and any modification in the natural fluorescence serves as an indication to implement the LIFEDT concept. Until the evidence of dentinal damage by the caries is definitely diagnosed using radiography

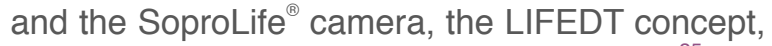
based on the work of Mertz-Fairhurst et al., ${ }^{25}$ recommends preventive sealing rather than a conventional irreversible mechanistic approach. This approach also opens up new prospects in terms of monitoring restorations. Indeed, any suspicious modification to the visible tissue fluorescence around existing restoration should facilitate a better diagnosis of recurrent caries.

\section{Conclusion}

An analysis of 50 occlusal grooves revealed three clinical forms of enamel caries: (1) enamel caries on the surface, (2) suspicious grooves with a positive autofluorescent red signal, and (3) suspicious grooves with a neutral fluorescent dark signal. Two decision-making diagrams were proposed in accordance with international recommendations for preventive dentistry but modified as a result of the accurate information obtained with this new LIFEDT device.

\section{Clinical Significance}

The lighting of suspect occlusal grooves with the SoproLife ${ }^{\circledR}$ camera enables observation of any variations in the optical properties to refine a caries diagnosis and facilitates a more than 50x magnification of occlusal groove anatomy to provide additional information on the carious potential of the tooth surface.

\section{References}

1. Lussi A. Comparison of different methods for the diagnosis of fissure caries without cavitation. Caries Res. 1993; 27(5):409-16.

2. Dommisch H, Peus K, Kneist S, Krause F, Braun A, Hedderich J, Jepsen S, Eberhard J. Fluorescence-controlled Er:YAG laser for caries removal in permanent teeth: a randomized clinical trial. Eur J Oral Sci. 2008; 116(2):170-6.

3. Banerjee A, Watson TF, Kidd EA. Dentine caries: take it or leave it? Dent Update. 2000; 27(6):272-6.

4. Banerjee A, Yasseri M, Munson M . A method for the detection and quantification of bacteria in human carious dentine using fluorescent in situ hybridisation. J Dent. 2002; 30(7-8): 359-63.

5. Banerjee A, Kidd EA, Watson TF. In vitro validation of carious dentin removed using different excavation criteria. Am J Dent. 2003; 16(4):228-30.

6. Pitts N. "ICDAS"-an international system for caries detection and assessment being developed to facilitate caries epidemiology, research and appropriate clinical management. Community Dent Health. 2004; 21(3):193-8.

7. Hall A, Girkin JM. A review of potential new diagnostic modalities for caries lesions. J Dent Res. 2004; 83 Spec No C:C89-94.

8. Erten H, Üçtasli MB, Akarslan ZZ, Üzun Ô, Semiz M. Restorative treatment decision making with unaided visual examination, intraoral camera and operating microscope. Oper Dent. 2006; 31(1):55-9.

9. Tyas MJ, Anusavice KJ, Frencken JE, Mount GJ. Minimal intervention dentistry - a review. FDI Commission Project 1-97. Int Dent J. 2000; 50(1):1-12.

10. Mount GJ, Tyas, JM, Duke ES, Hume WR, Lasfargues JJ, Kaleka R. A proposal for a new classification of lesions of exposed tooth surfaces. Int Dent J. 2006; 56(2):82-91.

11. Pitts NB. Modern concepts of caries measurement. J Dent Res. 2004; 83 Spec No C:C43-7. 
12. Bratthall D, Hänsel Petersson G.

Cariogram - a multifactorial risk assessment model for a multifactorial disease. Community Dent Oral Epidemiol. 2005; 33(4):256-64.

13. Featherstone JD, Domejean-Orliaguet $S$, Jenson L, Wolff M, Young DA. Caries risk assessment in practice for age 6 through adult. J Calif Dent Assoc. 2007; 35(10):703-7, 710-3.

14. Jenson L, Budenz AW, Featherstone JD, Ramos-Gomez FJ, Spolsky VW, Young DA. Clinical protocols for caries management by risk assessment. J Calif Dent Assoc. 2007; 35(10):714-23.

15. Ekstrand KR, Ricketts DN, Kidd EA, Qvist V, Schou S. Detection, diagnosing, monitoring and logical treatment of occlusal caries in relation to lesion activity and severity: an in vivo examination with histological validation. Caries Res. 1998; 32(4):247-54.

16. Ekstrand KR, Ricketts DN, Kidd EA. Occlusal caries: pathology, diagnosis and logical treatment. Dent Update. 2001; 28(8):380-7.

17. Ekstrand KR Improving clinical visual detection-potential for caries clinical trials. J Dent Res 2004; 83(Spec Iss C) : C67-C71.

18. Walsh LJ, Tsang AK. Chairside testing for cariogenic bacteria: current concepts and clinical strategies. J Minim Interv Dent. 2008; 1(2):126-49.

19. Midentistry.com [Internet]. Johannesburg, South Africa: midentistry corp. MI Clinical Dental Practice. Available from: http://www. midentistry.com/practice.html

20. Ahovuo-Saloranta A, Hiiri A, Nordblad A, Worthington $\mathrm{H}$, Mäkelä M. Pit and fissure sealants for preventing dental decay in the permanent teeth of children and adolescents. Cochrane Database Syst Rev. 2008; (4):CD001830. DOI: 10.1002/14651858. CD001830.pub3.

21. Rodrigues JA, Hug I, Diniz MB, Lussi A. Performance of fluorescence methods, radiographic examination and ICDAS II on occlusal surfaces in vitro. Caries Res. 2008; 42(4):297-304.

22. Ismail AI, Sohn W, Tellez M, Amaya A, Sen A, Hasson $\mathrm{H}$, Pitts NB. The International Caries Detection and Assessment System (ICDAS): an integrated system for measuring dental caries. Community Dent Oral Epidemiol. 2007; 35(3):170-8.
23. Adeyemi AA, Jarad FD, Pender N, Higham $\mathrm{SM}$. Comparison of quantitative light-induced fluorescence (QLF) and digital imaging applied for the detection and quantification of staining and stain removal on teeth. J Dent. 2006; 34(7):460-6.

24. Iwami $Y$, Hayashi N, Yamamoto $H$, Hayashi M, Takeshige F, Ebisu S. Evaluating the objectivity of caries removal with a caries detector dye using color evaluation and PCR. J Dent. 2007 35(9):749-54.

25. Mertz-Fairhurst EJ, Curtis JW Jr, Ergle JW, Rueggeberg FA, Adair SM. Ultraconservative and cariostatic sealed restorations: results at year 10. J Am Dent Assoc. 1998; 129(1): 55-66.

\section{About the Authors}

\section{Elodie Terrer, DDS}

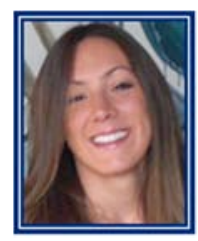

Dr. Terrer is a doctoral student in the Department of Restorative Dentistry of the Marseille Dental School at the University of the Mediterranean. Her major fields of interest are composite restorations and clinical research.

e-mail: elodieterrer83@hotmail.fr

\section{Stephen Koubi, DDS}

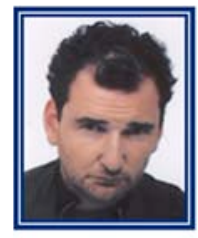

Dr. Koubi is a professor in the Department of Restorative Dentistry of the Marseille Dental School at the University of the Mediterranean. His major fields of interest are composite restorations, clinical research, and prosthetic dentistry.

\section{Alexandro Dionne}

Mr. Dionne is a dental student in the Department of Restorative Dentistry of the Marseille Dental School at the University of the Mediterranean. His major fields of interest are composite restorations and clinical research. 


\section{Gauthier Weisrock, DDS}

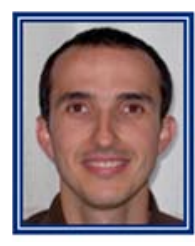

Dr. Weisrock is an Assistant Professor in the Department of Restorative Dentistry of the Marseille Dental School at the University of the Mediterranean. His major fields of interest are composite restorations and clinical research.

\section{Caroline Sarraquigne}

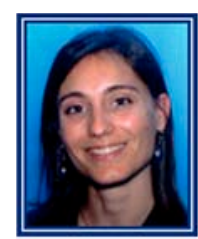

Ms. Sarraquigne is a biomedical engineer in Marseille, France, and a clinical development project manager in dental and medical research. Her major field of interest is to define and create product concepts with the potential of leading to the development of groundbreaking products.

\section{Alain Mazuir}

Mr. Mazuir is a biomedical engineer in La Ciotat, France, who is an inventor and patent specialist. His major field of interest is the creation of groundbreaking products associated with dental and medical imagery.

Hervé Tassery, DDS, MS, PhD (Corresponding Author)

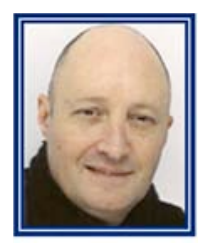

Dr. Tassery is a professor in the Department of Restorative Dentistry of the Marseille Dental School at the University of the Mediterranean. His major fields of interest are minimally invasive dentistry and clinical research.

e-mail: herve.tassery@numericable.fr 